Artículo Original

\title{
Diagnóstico del carcinoma basocelular pigmentado
}

\author{
DOI: https://doi.org/10.5377/alerta.v3i1.8684
}

\author{
Karla Elizabeth Morales Duarte' ${ }^{1}$, Ricardo Alberto Leal ${ }^{2}$ \\ 1. Estudiante de medicina en año social, Clínica médico odontológica Nazaret, San Salvador, El Salvador. \\ 2. Doctor en medicina y cirugía, dermatólogo. Centro dermatológico Leal, San Salvador, El salvador. \\ ${ }^{*}$ Correspondencia \\ Mkap150@hotmail.com \\ (D) 0000-0002-8107-6829
}

\section{G \\ ACCESO ABIERTO}

\section{Diagnosis of pigmented} basal cell carcinoma

\section{Citación recomendada: \\ Morales Duarte KE, Leal RA. \\ Diagnóstico del carcinoma \\ basocelular pigmentado. \\ Alerta 2020; 3(1):18-22. \\ DOI: https://doi.org/10.5377/ \\ alerta.v3i1.8684}

\section{Recibido:}

4 de noviembre de 2019

\section{Aceptado:}

9 de enero de 2020

\section{Publicado:}

27 de enero de 2020

\section{Contribución de autoría: \\ KEMD', RAL': Diseño y \\ redacción, recopilación de información, selección de imágenes, borrador del artículo, aprobación del manuscrito. RAL2: Descripción de las lesiones.}

\section{Conflicto de intereses:}

El estudio se realizó en una clínica privada, propiedad de uno de los autores.

\begin{abstract}
Resumen
El carcinoma basocelular es una de las neoplasias más comunes en seres humanos y es el más frecuente dentro del grupo de carcinomas cutáneos no melanoma. Se origina en células basales de la epidermis y folículos pilosos. Suele ser de lento crecimiento y poco agresivo y genera metástasis en la mayoría de los casos. El carcinoma basocelular tiene diferentes tipos, el nodular, ulcerativo, esclerodermiforme, pigmentado y el superficial. El tipo pigmentado posee la peculiaridad de ser confundido con otras patologías, como por ejemplo, con una queratosis seborreica, un melanoma maligno o un nevo azul, por lo que siempre es necesario investigar ante la sospecha clínica.

\section{Palabras clave}

Carcinoma basocelular, neoplasias, diagnóstico precoz.
\end{abstract}

\begin{abstract}
Basal cell carcinoma is one of the most common neoplasms in humans and, within a group of non-melanoma skin carcinomas, the most common one. Originated from epidermis basal cells and hair follicles, it grows slowly, it is not very aggressive and in most cases, it doesn't tend to emit metastases. Nonetheless, it has different cellular types: nodular, ulcerative, sclerosing, pigmented and superficial. The pigmented variant has the peculiarity of being confused with other pathologies such as seborrheic keratosis, malignant melanoma, and blue nevus, being mandatory to investigate on clinical suspicion.

Keywords

Basal cell carcinoma, neoplasms, early diagnosis.
\end{abstract}

\section{Introducción}

El carcinoma basocelular es la patología maligna más común de la piel', por lo tanto, debería ser buscada por todos los médicos al examinar al paciente en cualquier área clínica. El $80 \%$ de los carcinomas basocelulares se presenta en áreas fotoexpuestas ${ }^{2}$, como la cara, lo que facilita su detección durante el interrogatorio.

El carcinoma basocelular pigmentado, frecuentemente aparece en las zonas del cuerpo expuestas al sol, como por ejemplo la cabeza y el cuello, sin embargo, puede aparecer en cualquier zona. Existen áreas de riesgo para el aparecimiento del carci- noma, las cuales se clasifican en áreas de riesgo alto (llamada $\mathrm{H}$ por la palabra en inglés high). Esta abarca la cara (exceptuando frente y mejillas), genitales externos, palmas y plantas. El área de riesgo medio llamada también área $\mathrm{M}$ por Medium-Risk, abarca la piel cabelluda, frente, mejillas y cuello. El área de bajo riesgo, también llamada área L por Low-Risk, abarca el tronco y las extremidades ${ }^{2}$.

Las características generales que se deben buscar incluyen la transluscencia, y la ulceración, donde además se observan telangiectasias, pigmentación y borde enrollado perlado brillante. En fases tempranas el carcinoma basocelular pigmentado es 
pequeño, perlado, elevado con una delgada epidermis y con algunas telangiectasias. En general, todas las variedades clínicas pueden ser pigmentadas y ulceradas, con excepción del esclerodermiforme que no se ulcera. Muchos basocelulares pueden presentar sangramiento espontáneo, pero es raro que presenten dolor, ardor o prurito.

Existen varios subtipos clínicos de carcinomas basocelulares, entre ellos está el nodular, este es el subtipo clínico más común. Aparece como una lesión de aspecto papular o nodular, es traslúcido, dependiendo de la duración. Usualmente hay telangiectasias y bordes perlados. Puede ulcerarse tardíamente, además de reepitelizarse y desprenderse varias veces antes de que la ulceración se haga permanente 3 . El carcinoma basocelular superficial ocurre más frecuentemente en el tronco y aparece como una placa eritematosa bien demarcada y generalmente se descama ${ }^{3}$. El carcinoma morfeiforme (esclerodermiforme) es variante, con un crecimiento agresivo y con diferente apariencia clínica e histológica. Las lesiones pueden tener un color blanco marfilis.

El carcinoma ulcerado es de aspecto carnoso, no muy vascularizado y friable. En esta variante, el borde de la úlcera se sobre eleva y el piso de la úlcera está deprimido. Puede causar una gran destrucción, especialmente alrededor del ojo, la nariz o la oreja, huesos de la cara, el cráneo e incluso las meninges ${ }^{4}$. Finalmente, el carcinoma pigmentado combina algunas características anteriores y puede tener un aspecto brillante y traslucido. Este adquiere un pigmento, especialmente los nodulares, pero también puede encontrarse pigmento en los ulcerados ${ }^{3}$.

En El Salvador, muchos pacientes no son diagnosticados cuando el carcinoma es de tamaño pequeño, sino cuando estos evolucionan y causan lesiones destructivas. Generalmente, este problema no es detectado por muchos médicos en el primer y segundo nivel de atención o es confundido con otras patologías. Aunque no se han publicado estudios en El Salvador sobre este tema, se estima que el cáncer de piel (incluyendo melanoma y no melanoma) es el segundo cáncer más diagnosticado en el Instituto Salvadoreños del Seguro Social. Por lo tanto, se presenta una serie de casos con el objetivo describir las formas de presentación de un carcinoma basocelular pigmentado y sus posibles diagnósticos diferenciales.

\section{Metodología}

Estudio de serie de casos clínicos de carcinoma basocelular pigmentado diagnosticado clínicamente y a través de biopsia. La selección y clasificación de los pacientes con carcinomas basocelulares pigmentados se realizó a través de la revisión de expedientes clínicos de casos atendidos entre el año 2009 al 2018. Todos los pacientes fueron atendidos en una clínica privada del de departamento de San Salvador. Se seleccionaron a nueve pacientes que presentaban diferente estadio de evolución y aspecto del carcinoma pigmentado los cuales fueron confirmados a través de biopsia. Previo a la obtención de los datos, se obtuvo el consentimiento de los pacientes involucrados en el estudio.

\section{Resultados}

Los carcinomas fueron encontrados con mayor frecuencia en mujeres, más comúnmente en el área facial, en zonas fototipos I, II y III. La mayoría de pacientes presentan daño solar o historia de abundante exposición solar durante su infancia.

Caso 1. Mujer de 73 años de edad con una tumoración nodular de $0.4 \mathrm{~cm}$ de diámetro, de aspecto cupuliforme, bien limitada y pigmentada parcialmente, localizada en el mentón (Figura 1). Esta paciente tenía una evolución de 8 meses y la lesión era asintomática. En este caso, el diagnóstico diferencial puede incluir un nuevo melanocítico intradérmico.

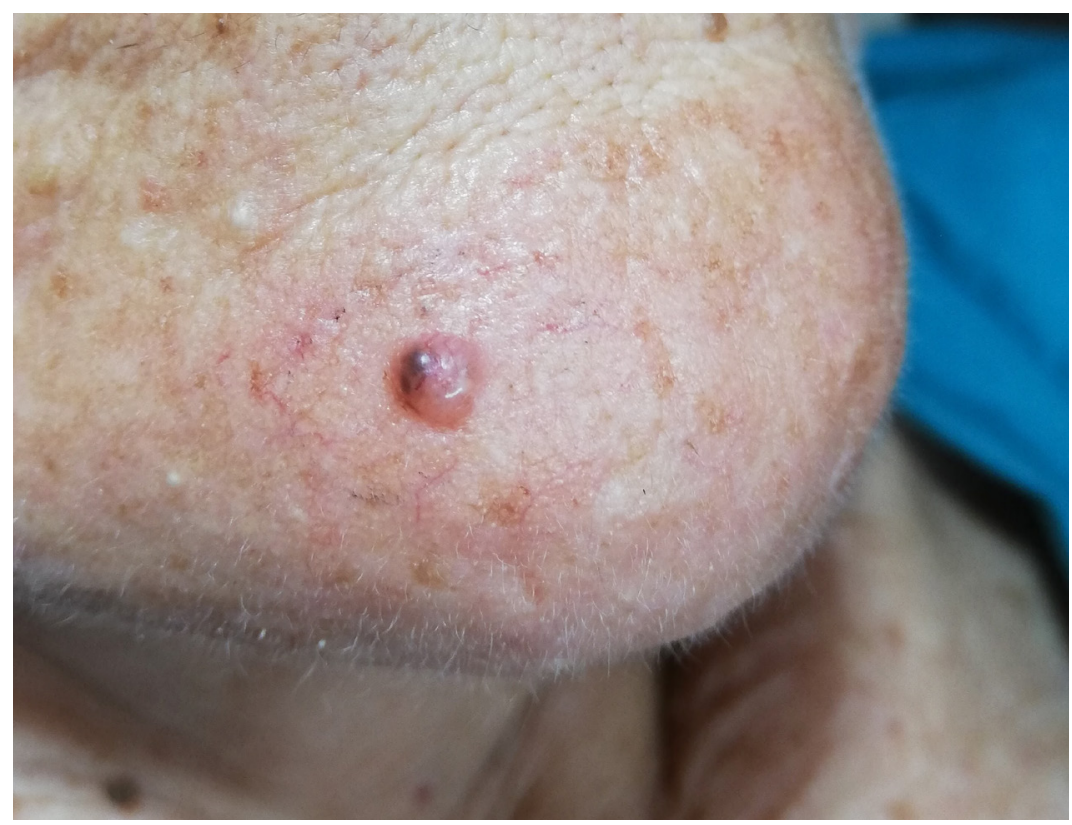

Figura 1. Tumoración nodular de $0.4 \mathrm{~cm}$ de diámetro

Caso 2. Mujer de 66 años de edad que presentaba una tumoración pigmentada bien delimitada de $0.5 \mathrm{~cm}$ de diámetro en la nariz (Figura 2), con 5 años de evolución sin presentar síntomas. El pigmento era más oscuro en el centro y se difuminaba en la periferia de la lesión. En este caso se puede pensar como diagnóstico diferencial en un nevo melanocítico. 


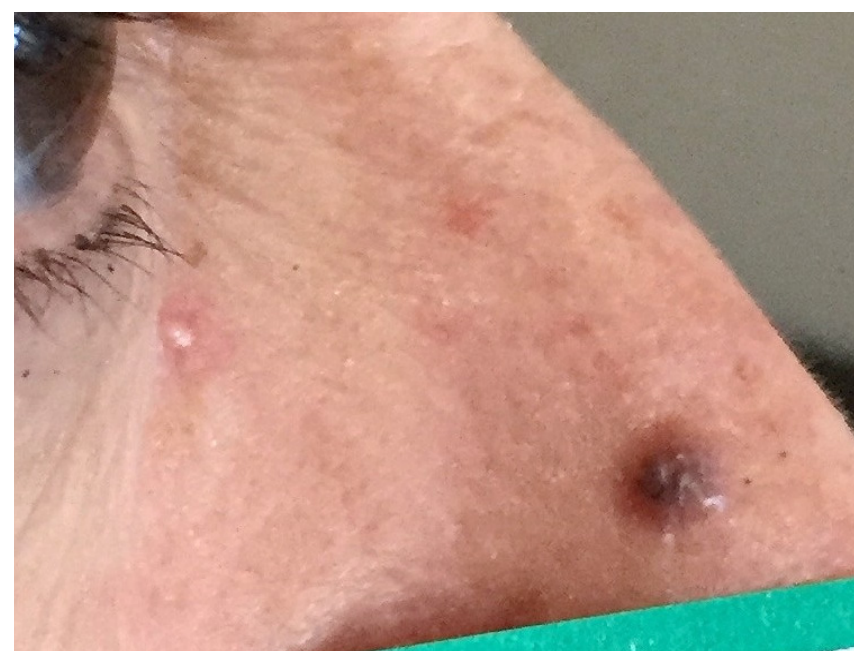

Figura 2. Carcinoma basocelular de $5 \mathrm{~cm}$ de diámetro de lento crecimiento

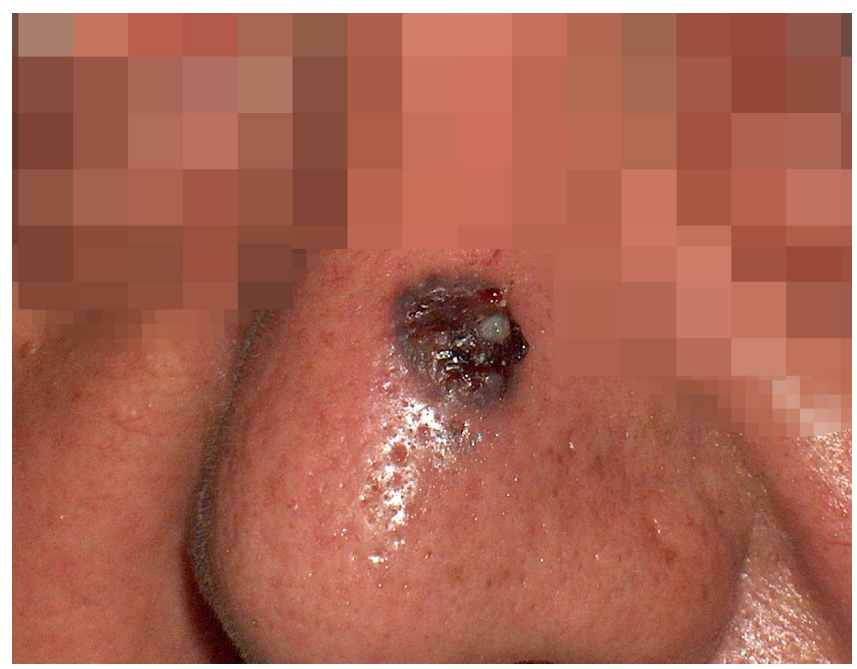

Figura 4. Carcinoma basocelular pigmentado y ulcerado de $1 \mathrm{~cm}$ de diámetro

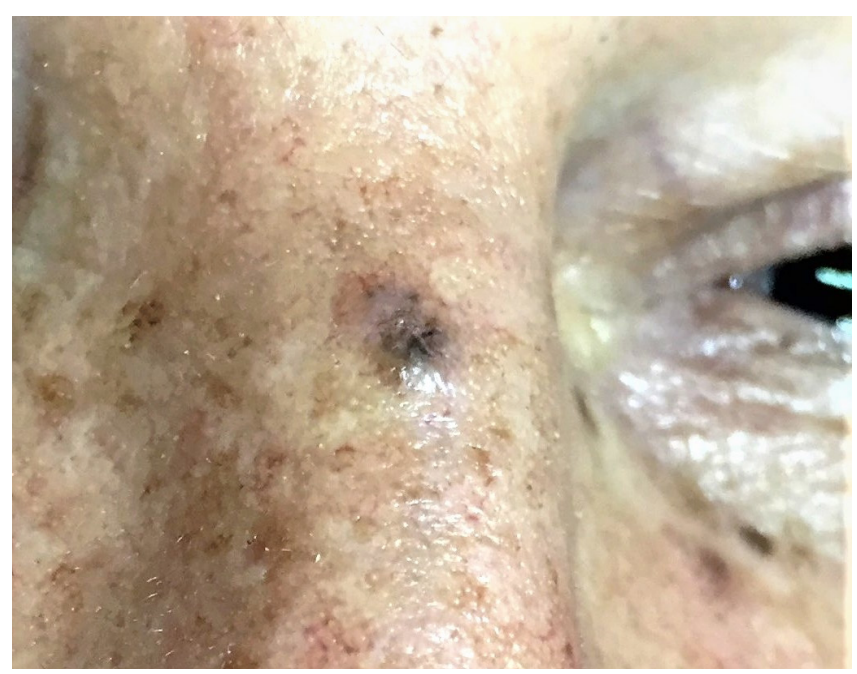

Figura 6. Tumoración de $0.5 \mathrm{~cm}$, cupuliforme, pigmentada en la pirámide nasal

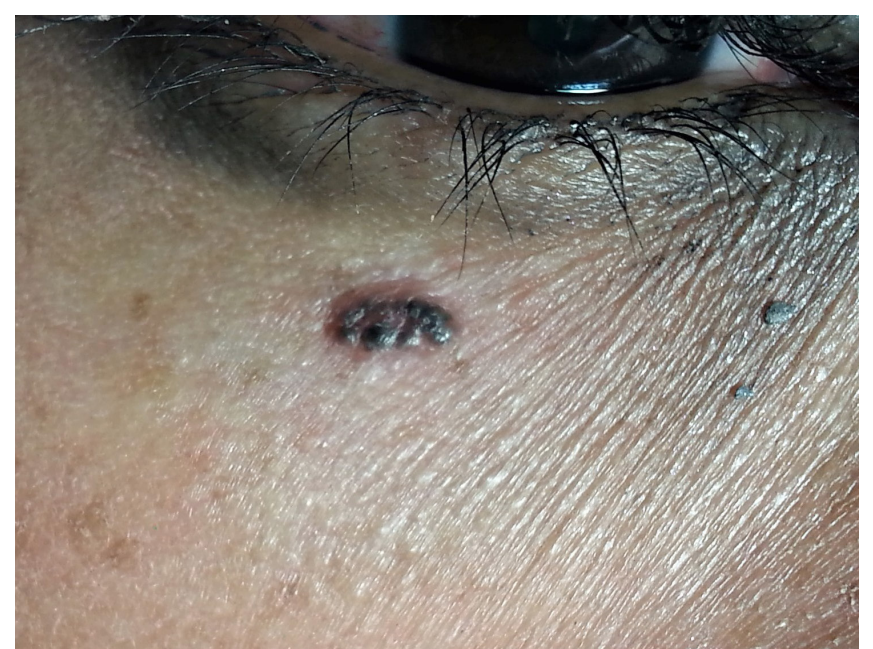

Figura 3. Carcinoma basocelular pigmentado en el párpado inferior derecho

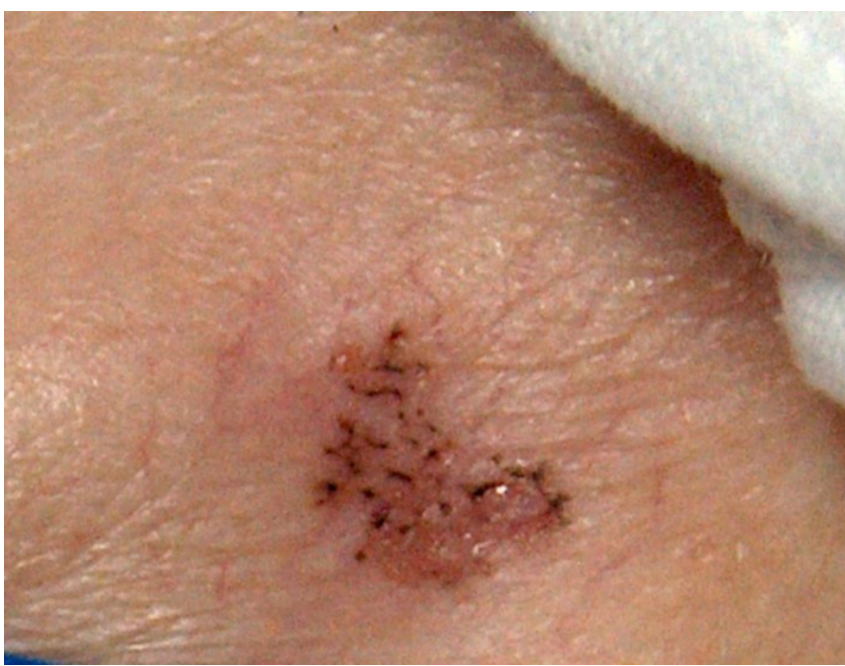

Figura 5. Carcinoma basocelular de 1.2 × 0.7 cm en la región clavicular izquierda

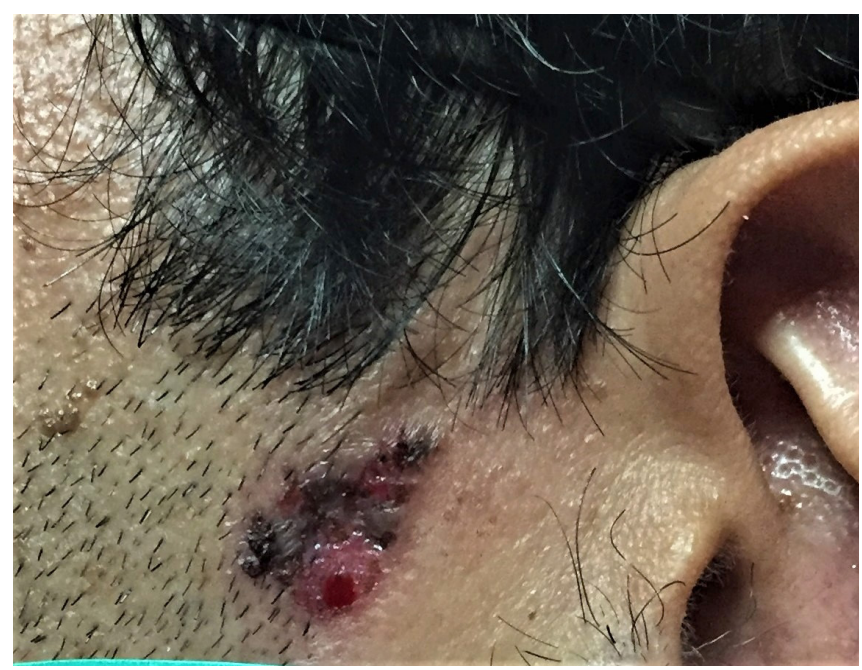

Figura 7. Neoformación pigmentada de $1.5 \mathrm{~cm}$ en la región pre auricular izquierda 


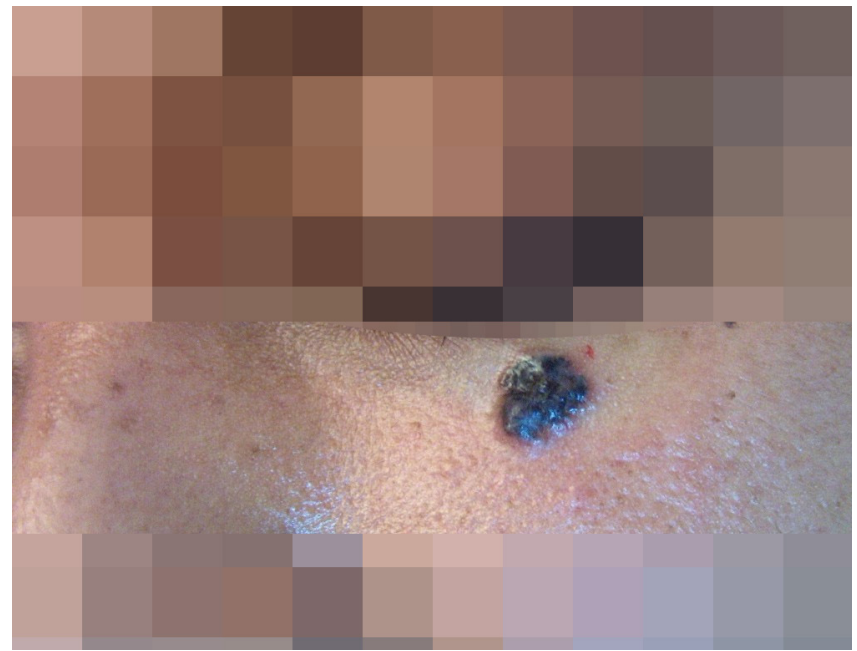

Figura 8. Carcinoma basocelular pigmentado en mujer joven

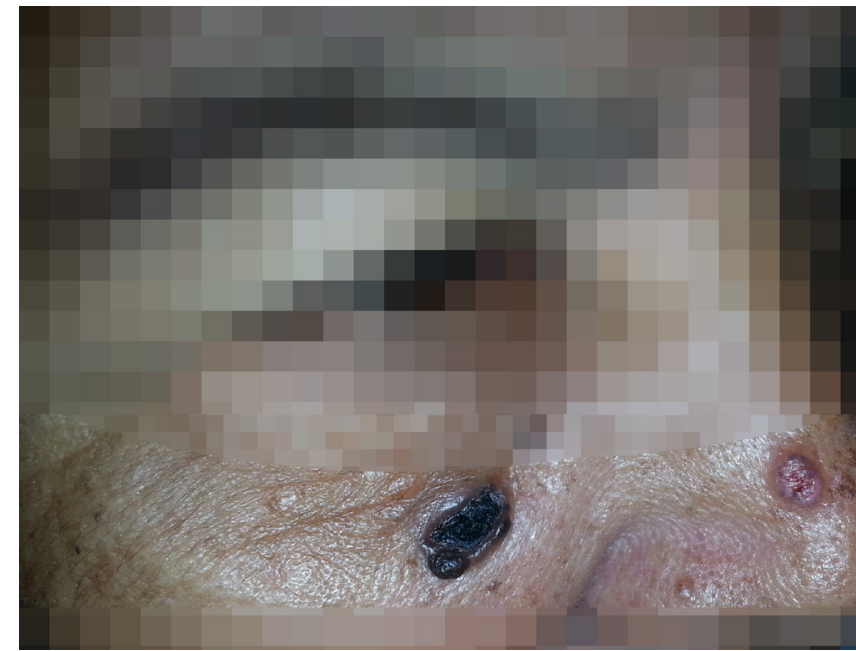

Figura 9. Carcinoma basocelular pigmentado
Caso 3. Mujer de 36 años de edad con un carcinoma basocelular pigmentado de 0.5 cm en el párpado inferior derecho (Figura 3), con historia de extirpación de hace 5 años sin previo estudio patológico y con recidiva de hace 2 años. En este caso, el carcinoma inició cuando la paciente tenía 31 años de edad. Para este caso se puede hacer referencia a una queratosis seborreica y un melanoma cutáneo como diagnóstico diferencial.

Caso 4. Hombre de 73 años con un carcinoma basocelular pigmentado y ulcerado de $1 \mathrm{~cm}$ de diámetro ubicado en la nariz (Figura 4), con 9 meses de evolución, friable y con sangramiento ocasional.

Caso 5. Hombre de 77 años de edad con un carcinoma basocelular de $1.2 \times 0.7 \mathrm{~cm}$ en la región clavicular izquierda (Figura 5). La lesión presentaba una pigmentación reticulada negra con dos puntos de ulceración, con evolución desconocida por el paciente, debido a la localización.

Caso 6. Mujer de 65 años de edad con una tumoración de $0.5 \mathrm{~cm}$, cupuliforme, pigmentada y bien limitada en la pirámide nasal (Figura 6) con 11 meses de evolución la cual había iniciado como un pequeño lunar. A través de la biopsia se demostró que se trataba de un carcinoma basocelular sólido. Con el examen físico se identificó un daño actínico crónico en cara y escote manifestado a través de telangiectasias, atrofia y queratosis actínicas.

Caso 7. Hombre de 52 años de edad con una neoformación pigmentada de $1.5 \mathrm{~cm}$ ubicada en la región pre auricular izquierda (Figura 7). La lesión estaba ulcerada en uno de sus extremos y cubierta de una costra hemática de fácil desprendimiento y san- grado. La neoformación inició como un lunar, evolucionando hasta producir líquido serosanguinolento. El paciente presentaba un fototipo de piel tipo III.

Casos 8 y 9. Se presentan dos pacientes con carcinomas basocelulares pigmentados en la misma topografía. La figura 8 muestra una mujer de 35 años y la figura 9 a una mujer de 60 años. En ambos casos, el diagnóstico diferencial puede ser una queratosis seborreica o un melanoma cutáneo. Ambas lesiones presentan predominio de pigmento negro, con un área central de tono azulado con borde protuberante y brillante.

En el caso 8 el diagnóstico diferencial debe realizarse con la variedad de nevos melanocíticos. En el caso 9 se debe diferenciar la lesión de un carcinoma basocelular pigmentado y queratosis seborreicas (Figura 9). En este caso se realizó una biopsia de la lesión la cual confirmó la sospecha diagnóstica. Posteriormente se extirpó la lesión.

\section{Discusión}

El carcinoma basocelular es el cáncer más común en humanos y su incidencia va en incremento ${ }^{5}$. Es una neoplasia que se origina de células pluripotenciales de la zona basal de la epidermis y de los folículos pilosos, específicamente de la vaina radicular externa. Se presentan con mayor frecuencia en la nariz en personas de la tercera edad, principalmente en aquellas que han estado expuestas duramente jornadas largas al sol intenso sin protección.

Es poco frecuente observar carcinomas basocelulares en personas menores de 40 años. Sin embargo, es importante destacar los casos de carcinoma basocelular en pacientes menores de 30 años. Esto podría deberse a que El Salvador presenta altos 
índices de radiación $U V$, que a horas del mediodía puede alcanzar valores de 9 y $10^{6}$. La mayoría de población estudiada presenta fototipo II y III, aunque generalmente los carcinomas basocelulares aparecen en fototipos III y IV.

Entre otros factores de riesgo, se describe la presencia de un gran número de nevos, pecas y elastosis solar, personas blancas que no se broncean fácilmente (fototipos I y II) con historia de quemaduras solares, principalmente en la infancia o personas cuya profesión incluye mayor exposición solar, como jardineros, campesinos y pescadores. Otro factor de riesgo son los antecedentes familiares, estos aumentan la susceptibilidad a desarrollar un carcinoma basocelular.

Los carcinomas tienen un crecimiento radial de aproximadamente $1 \mathrm{~cm}$ por año, lo que concuerda con la evolución del caso 4. Sin embargo, el promedio de crecimiento en la mayoría de los carcinomas basocelulares descritos en este estudio es de medio centímetro por año.

No es común que un carcinoma presente una pigmentación parcial reticulada o puntiforme, usualmente la pigmentación se produce en áreas grandes dentro de la tumoración. Esta es una morfología poco usual para un carcinoma basocelular, pero debido a su pigmentación irregular. En algunos casos el pigmento se presenta como áreas planas y puede ser que los carcinomas basocelulares más extensos presenten secreciones o costras, tal como se muestra en el caso 6.

Las neoformaciones suelen sangrar y pueden presentarse como protuberancias de color rosado, rojo o negro y con áreas azuladas, brillante o apariencia nacarada (Figura 7). En algunas ocasiones los carcinomas basocelulares pueden tener pigmento solo en una zona de la lesión, el brillo que reflejan con la luz también es característico y puede ser una clave diagnóstica. El carcinoma basocelular puede aparecer como relieves en la piel, que puede ser de color rosado, rojizo o un pigmento más oscuro y puede incluir vasos anormales en su superficie.

Cuando se extirpan lesiones, aunque parezcan simples nevos, siempre se debe hacer un estudio histológico. Y en el caso de una lesión con sangramiento y sin dolor, siempre debe sospecharse de una malignidad. Para la caracterización epidemiológica y una mejor detección, es importante indagar que edad tenía la persona cuando apareció por primera vez la lesión y la ubicación de la lesión.

\section{Conclusiones}

El carcinoma basocelular pigmentado es el cáncer de piel más común en hombres y mujeres menores de 50 años. Se localiza principalmente en la cabeza y el cuello, con una predilección particular por la parte central superior de la cara. Generalmente es asintomático y de lenta evolución.

\section{Agradecimientos}

Se agradece a los pacientes quienes cooperaron desde el momento de la sospecha diagnóstica y accedieron a participar en el estudio según consentimiento informado, para reproducir las imágenes, hacer biopsia y llevar continuidad de su lesión.

\section{Financiación}

El estudio se realizó dentro del centro dermatológico Leal, con los equipos y recursos del mismo.

\section{Referencias Bibliográficas}

1. Kim JYS, Kozlow JH, Mittal B, Moyer J, Olencki T, Rodgers P, et al. Guidelines of care for the management of basal cell carcinoma. Journal of the American Academy of Dermatology. Elsevier BV; 2018; 78(3):540-59. DOI: https://doi.org/10.1016/j. jaad.2017.10.006

2. Pérez DA, Bojórquez AM, González ST, Franco GN, Garibay AR, Pedrero MLP, et al. Correlación clínica, histológica y dermatoscópica del carcinoma basocelular. Rev Cent Dermatol Pascua 2013; 22 (1):5-14.

3. Wolff K, Johnson RA, Saavedra AP. Fitzpatrick Atlas de dermatología clínica. 7a edición. Mc Graw Hill Education. México D.F; 2014.

4. Burn T, Breathnach S, Cox N, Griffiths C. Rook's Textbook of Dermatology. 8th Edition. Wiley-Blackwell Editors. Singapore; 2010. Disponible en: https://bit.ly/2vuiySy

5. Cameron MC, Lee E, Hibler BP, et al. Basal cell carcinoma: Contemporary approaches to diagnosis, treatment, and prevention. J Am Acad Dermatol. 2019; 80(2):321-339. DOI: https://doi.org/10.1016/j.jaad.2018.02.083

6. Júarez CA, Pohl M, Clímaco J, Cisneros A, Valencia O, Escobar H. UVmaforo: Monitoreo del Indice UV en El Salvador. UCA; 2017 Jul 12; Disponible: https://bit.ly/37ABYU2 